\title{
Preoperative versus Intraoperative Intravenous Tranexamic Acid Efficacy in Reducing Blood Loss in Hip Fracture Surgeries: A Randomized Controlled Trial
}

\author{
Ahmed A.Mahmoud, Hani A. Bassioony, Ahmed A. Elsheikh
}

Department of Orthopedics, Benha faculty of medicine, Banha University, Egypt.

Correspondence to: Ahmed A. Mahmoud, Department of Orthopaedics, Benha faculty of medicine, Benha University, Egypt.

\section{Email:}

dr.ahmedhasham@gmail.com

Received: 15 December 2020

Accepted:9 February 2021

\begin{abstract}
:
Background: Hip fracture is common, with the reported lifetime prevalence of $20 \%$ for women and $10 \%$ for men. Despite recent advances in the techniques and instrumentation of orthopedic procedures, however, hip fracture surgery is still commonly associated with substantial blood loss, subsequent acute anaemia, and the need for transfusion. Postoperative anaemia in patients with hip fracture may lead to decreased ambulation, reduced functional independence and reduced walking distance on discharge Objective: To evaluate the efficacy of preoperative vs. intraoperative IV-TXA on postoperative blood loss following hip fracture surgery. Patients and Methods: A prospective randomized controlled study that was held on thirty adult patients with hip fracture who had a surgery. Results: The drains were removed in day 2. Mean volume of blood in the drain at day 0 was
\end{abstract} $140.00 \pm 60.36 \mathrm{ml}$ in group A as compared to $163.33 \pm 66.73 \mathrm{ml}$ in group B. Mean volume of blood in the drain at day 2 was $142.00 \pm 85.54 \mathrm{ml}$ in group A as compared $123.33 \pm 56.27 \mathrm{ml}$ in group B. Conclusion: The present study demonstrated that there is no significant difference between preoperative versus intraoperative IV-TXA in reducing blood loss in patients undergoing surgeries for hip and proximal femoral fractures. Additionally TXA administration in both groups caused a reduction in postoperative anemia and need for transfusion without significantly increasing the risk of thromboembolic events including DVT. This would in turn, help to avoid complications related with transfusion of blood and blood products.

Keywords: Intravenous tranexamic acid, blood loss, hemoglobin 


\section{Introduction}

Hip fracture is common, with the reported lifetime prevalence of $20 \%$ for women and $10 \%$ for men in the United States ${ }^{[1]}$. A national epidemiological study in China reported a higher incidence among older people ${ }^{[2]}$. Despite recent advances in the techniques and instrumentation of orthopedic procedures, however, hip fracture surgery is still commonly associated with substantial blood loss, subsequent acute anaemia, and the need for transfusion ${ }^{[3]}$. Postoperative anaemia in patients with hip fracture may lead to decreased ambulation, reduced functional independence and reduced walking distance on discharge ${ }^{[4]}$. Patients with anaemia have a lower recovery rate of physical disability than those without anaemia $^{[5]}$.

Thus, loads of techniques have been applied for blood management, including application of tourniquet, thromboplastic agents, topical freezing saline, deliberate hypotension, fibrinolytic inhibitors, blood transfusion and autologous donation ${ }^{[6]}$; of which, the allogeneic blood transfusion is the most commonly used strategy. In a previous study, the transfusion rate of allogeneic blood could reach as high as $84 \%$ [7]. However, allogeneic blood transfusion may increase the risk of adverse effects such as virus infection, immune response and cardiovascular dysfunction and even death, causing financial burden and a potential threat for patients ${ }^{[8]}$. Meanwhile, the current medical care standard recommends conservative and limited utilization of blood products ${ }^{[9]}$, which underlines the need for better control of bleeding.

Tranexamic acid (TXA) is a synthetic amino acid that carries out its effects through an anti-fibrinolytic action. It stabilizes formed clots and prevents the degradation of fibrin by reversibly inhibiting the lysine binding site on plasminogen. It can destroy plasminogen's linkage with fibrin to become plasmin, which normally creates a fibrinolytic effect and dissolves clots ${ }^{[10]}$. Through reducing fibrinolysis, it helps to decrease bleeding and blood loss resulting from the trauma of surgery and the release of tissue plasminogen activator ${ }^{[11]}$.

Recently, numerous studies have proved that intravenous (IV) TXA could reduce perioperative blood loss and transfusion requirements without increasing the risk of thrombosis during joint arthroplasty ${ }^{[12]}$. Also recent studies have reported that IVTXA efficaciously reduces TBL and transfusion requirements during hip fracture surgery without significantly increasing the 
risk of thromboembolic events including $\operatorname{DVT}^{[13]}$.

Most of the included studies reported preoperative-only or preoperative plus postoperative IV-TXA, and the total dose ranged from $10 \mathrm{mg} / \mathrm{kg}$ to $1-4 \mathrm{~g}$, so the optimal timing and dosage of IV-TXA are still unclear ${ }^{[14]}$.

We conclude from the above the extent of importance of IV-TXA in reducing postoperative blood loss and transfusion requirements during hip fracture surgery, but the optimal timing of administration remains a perplexing matter. Therefore, we will address in this study the optimal timing of IV-TXA in hip fracture surgery, is it preoperative or intraoperative?

\section{Aim of the work}

The aim of this study is to evaluate the efficacy of intraoperative vs. postoperative IV-TXA on postoperative blood loss following hip fracture surgery.

\section{Patients and methods}

A prospective randomized controlled study held on thirty adult patients with hip fracture undergoing a surgery.

\section{Patients \& study subjects:}

Inclusion criteria: (1) Patients with an established diagnosis of proximal femur fracture managed by DHS, DCS, proximal femoral plate or open reduction and nailing, (2) Patients with an established diagnosis of femoral neck fracture managed by hemiarthroplasty or primary total hip in case of acetabular problems and (3) Anatomical distribution in limbs: proximal femur and neck of Femur.

Exclusion criteria: (1) Patients with an established diagnosis of proximal femur fracture managed by closed reduction and nailing, (2) Polytrauma patients (two or more severe injuries in at least two areas of the body), (3) Patients allergic to TXA, (4) Preoperative renal impairment (creat. $>2$ mg\%), (5) Preoperative hepatic impairment $(\mathrm{INR}>1.5$ or liver enzymes elevated by $>3$ times to normal range), (6) Known bleeding disorders or preoperative coagulation anomaly, (7) History of thromboembolic events such as MI, cerebrovascular accidents, PE, DVT or arterial thrombosis.

The study was carried out in Almataria teaching hospital from March 2020 to October 2020.

The study was approved by the institutional Ethics Committee and written informed consent was obtained from each patient.

Patients fulfilling the inclusion criteria are blindly divided into two groups. 
Randomization was done by opaque sealed envelope technique.

Group A: receiving a bolus intravenous injection of $(15 \mathrm{mg} / \mathrm{kg})$ TXA through $50 \mathrm{ml}$ syringe during $10 \mathrm{~min}$ about $15 \mathrm{~min}$ prior to skin incision.

Group B: receiving continuous infusion of 1 $\mathrm{mg} / \mathrm{kg} / \mathrm{h}$ TXA dissolved in 1 lit of saline until the completion of surgery.

Preoperatively, the hemoglobin concentration, bleeding time, clotting times were measured on the day before operation. The anesthetist administrating the drug was unaware of TXA being given. Surgery was performed under spinal anesthesia. Hemodynamics (heart rate, systolic, diastolic and mean arterial blood pressure (MABP)) was noted starting from preoperational to shifting at regular intervals of $30 \mathrm{~min}$. Ringer's solution was used as the replacement fluid for the estimated intraoperative blood volume lost in a 3:1 ratio. There was no significant difference in amount of fluid in both groups. A low-vacuum drain is inserted in the sub-muscular plane Postoperatively, All the following data were documented on day 0 (day of surgery at $20.00 \mathrm{hr}$ ) and day2: Haemoglobin levels, volume of blood in the drain, the number of units of packed red cells transfused during the hospital stay. (The indication for blood transfusion is set at haemoglobin level $<8.5$ $\mathrm{g} / \mathrm{dl}$ ) and any thromboembolic and other complications are documented.

Statistical analysis was performed using SPSS 21.0 statistical software (SPSS Inc., Chicago, Ill., USA). Means are presented as mean \pm standard deviation. T-test was used to compare numerical data, while measurement data was compared by Chisquare test. A p-value of less than 0.05 was considered significant.

\section{Results}

The mean age of the patients in group A was $62.27 \pm 7.31$ years and $61.93 \pm 10.00$ years in group B ( $p$ value 0.918$)$. (53.3\%) of the patients in group A were females and (46.7\%) were males as opposed to $(60.0 \%$ females) and (40.0\% males) in group B (p value 0.136). The mean preoperative haemoglobin $11.93 \pm 1.52 \mathrm{gm} \%$ in group A as compared to $12.39 \pm 1.69 \mathrm{gm} \%$ in group B ( $p$ value -0.771) (Table 1). There were no significant differences between the patients with respect to age, sex and preoperative mean hemoglobin concentration.

The drains were removed in day 2. Mean volume of blood in the drain at day 0 was $140.00 \pm 60.36 \mathrm{ml}$ in group A as compared to $163.33 \pm 66.73 \mathrm{ml}$ in group B showing no statistically significant difference in postoperative blood loss ( $\mathrm{P}$ value 0.324). Mean volume of blood in the drain at day 2 
was $142.00 \pm 85.54 \mathrm{ml}$ in group $\mathrm{A}$ as compared $123.33 \pm 56.27 \mathrm{ml}$ in group $\mathrm{B}$ showing no statistically significant difference in postoperative blood loss (P value 0.486) (Table 2). Mean hemoglobin level at day 0 was $10.53 \pm 1.54 \mathrm{gm} \%$ in group $\mathrm{A}$ as compared to $10.63 \pm 1.86 \mathrm{gm} \%$ in group $\mathrm{B}$ that has $\mathrm{P}$ value 0.873 showing no statistically significant difference. Mean hemoglobin level at day 2 was $9.95 \pm 1.25$ gm \% in group A as compared to $10.38 \pm$ 1.32 gm \% in group B that has $\mathrm{P}$ value 0.362 showing no statistically significant difference. In our study out of 30 patients, 10 patients required blood transfusion and Table (2) shows there was no statistically significant difference found between group A and group B as regarding blood transfusion in day 0 and the same in day 2 .

Table 3 shows comparison between (preoperative vs day0 vs day 2) regarding $\mathrm{HB}$ in group $\mathrm{A}$ and group $\mathrm{B}$ and this table shows there was highly significant difference found between (preoperative Vs day 0) and (preoperative vs day 2) in group $\mathrm{A}$ and group $\mathrm{B}$ and also shows there was no significant difference found between (day 0 vs day 2) regarding HB in both groups.

No significant complications like thromboembolic episodes were encountered in both groups

Table 1:

\begin{tabular}{|c|c|c|c|c|c|c|}
\hline & & Group A (Pre TXA) & Group B (Intra TXA) & Test value & P-value & Sig. \\
\hline & & No. $=15$ & No. $=15$ & & & \\
\hline \multirow[t]{2}{*}{ Age (yrs) } & $\operatorname{Mean} \pm$ SD & $62.27 \pm 7.31$ & $61.93 \pm 10.00$ & $0.104 \bullet$ & 0.918 & NS \\
\hline & Range & $50-80$ & $45-81$ & & & \\
\hline \multirow[t]{2}{*}{ Sex } & Female & $8(53.3 \%)$ & $9(60.0 \%)$ & $0.136^{*}$ & 0.713 & NS \\
\hline & Male & $7(46.7 \%)$ & $6(40.0 \%)$ & & & \\
\hline Pre operative $\mathbf{H b}$ & Mean \pm SD & $11.93 \pm 1.52$ & $12.39 \pm 1.69$ & $-0.771 \bullet$ & 0.447 & NS \\
\hline$(\mathrm{g} / \mathrm{dL})$ & Range & $10-15$ & $10-16$ & & & \\
\hline
\end{tabular}


Table 2:

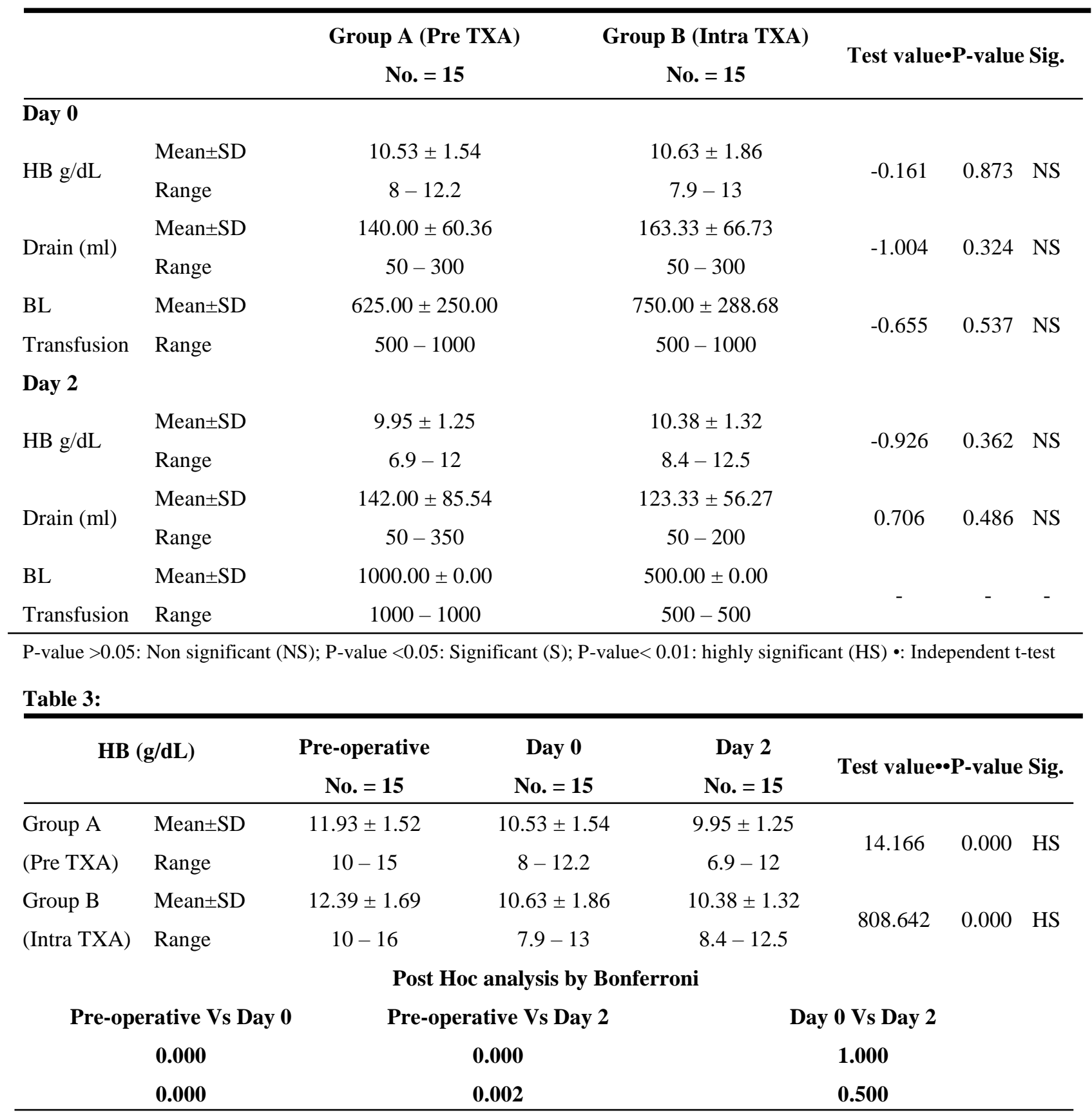

P-value >0.05: Non significant (NS); P-value <0.05: Significant (S); P-value $<0.01$ : highly significant (HS)

$\$$ : Mann Whitney teat 


\section{Discussion}

To our knowledge this would be the first study to compare preoperative IV TXA versus intraoperative IV TXA. We found

that there is no significant difference between preoperative versus intraoperative IV-TXA in reducing blood loss in hip fracture surgeries

The present study is a prospective randomized controlled study on 30 patients who underwent hip fracture surgeries. This coincides with several studies (15-18) which were also randomized controlled studies which compared TXA to control on patients who underwent hip fracture surgeries. However, other studies (19 \& 20) were retrospective studies to evaluate the efficacy and safety of IV TXA in hip fracture surgeries with no controls.

We have included ORIF of proximal femoral fractures, hemiarthroplasty and primary THR, in agreement with others (15, 16, $17 \&$ 18). While other studies were conducted solely on THR or TKR (21-22)

In the present study we have compared between two groups both received IV TXA to determine the optimal time to take it during hip fracture surgeries, while most of other studies $(15,17,18 \& 23)$ compared TXA to control group to evaluate the efficacy and safety of IV TXA in hip fracture surgeries. These studies concluded that IV TXA reduces transfusion requirements, total blood loss and without increasing the incidence of thromboembolic events in patients undergoing hip surgeries. Other studies (17 \& 24) assessed the efficacy of topical TXA.

Some researchers (17) investigated 137 patients who underwent peritrochanteric fracture surgery divided into 2 groups. One group received $2 \mathrm{gm}$ of topical and subfacial infiltration of TXA. A study was conducted on 200 patients (24) who underwent intertrochanteric fracture surgery by intramedullary nail. The patients in the treatment group received $3 \mathrm{~g}$ of tranexamic acid in the sub-fascial plane and around the fracture site. Forty three \% reductions in transfusion requirements was reported (24) in contrast to a different study (17) where no any significant difference between 2 groups was reported.

In most of reported studies as well as the present study, the effect of IV tranexamic acid was assessed based on various parameters related to blood loss like drain 
output, haemoglobin drop and requirement for blood transfusion during surgeries for fixation of hip fractures.

In the present study there was no significant difference between the two groups in postoperative blood loss either in day 0 and in day 2, Also we found that there is no statistically significant difference between two groups as regard mean haemoglobin level and transfusion requirements. In atrial group, IV TXA was given preoperatively $(15,18 \& 25)$. There was highly significant reduction in the Postoperative blood loss in TXA group. Also mean haemoglobin level and transfusion requirements were significantly better in the TXA group in all of these studies.

In a related study, 77 patients with intertrochanteric fracture were treated by PFNA received IV TXA preoperatively in TXA group and normal saline in control group. Postoperative blood loss has no significant difference between the two groups. However, postoperative transfusion rate was significantly lower in the TXA group compared to the control group versus control $(\mathrm{P}=0.01)(27)$.

In a study published 2018, (16) 50 of 100 patients underwent intertrochanteric fracture surgery (PFNA) received IV TXA $15 \mathrm{~min}$ before surgery and $5 \mathrm{hrs}$ postoperatively (TXA group) and other 50 received normal saline (control group). There was statistically significant difference in postoperative blood loss, haemoglobin and transfusion requirements in both groups. These results were achieved also in another study (28) in which IV TXA was given preoperatively and intraoperative infusion until surgery completion.

A study was conducted on cementless THR (26), and found a significant reduction in postoperative blood loss in TXA group than in the control group as well as in hemoglobin and hematocrit values. This coincides with the study conducted on 42 patients who underwent TKR showing high significant difference between 2 groups as regard postoperative blood loss (21).

As regard thromboembolic complications of TXA like DVT, pulmonary embolism, acute coronary syndrome, or myocardial infarction, we did not report any abnormal finding in both groups during the follow up. This comes in agreement with other studies $(15,17 \&$ 18) where no patient had thromboembolic adverse events.

In other studies, three patients in the TXA group experienced DVT in the lower limbs, compared with two patients in the control 
group with no statistically significant difference between the two groups. Also in lei et al two patients in TXA group presented by DVT in the lower limbs,

Although our study is prospective, it has certain limitations; the sample size is relatively small. The present study was not double-blinded. The surgeries were not performed by a single surgeon, thereby leading to differential expertise amongst different surgeons. We looked for the side effects of tranexamic acid only up to two weeks when the patient reported for suture removal. Any potential complications that could have presented later have not been accounted for. We could also not compare our results to the use of combined intravenous and local tranexamic acid. A larger randomized controlled trial might be needed to confirm our findings.

\section{Conclusion}

The present study demonstrated that there is no significant difference between preoperative versus intraoperative IV-TXA in reducing blood loss in patients undergoing surgeries for hip and proximal femoral fractures. Additionally TXA administration in both groups caused a reduction in postoperative anemia and need for transfusion without significantly compared with one patient in the control group with no statistically significant difference between the two groups (16) increasing the risk of thromboembolic events including DVT. This would in turn, help to avoid complications related with transfusion of blood and blood products.

\section{References}

1. Landefeld CS (2011): Goals of care for hip fracture: promoting independence and reducing mortality. Arch Intern Med 171(20):1837-1838.

2. Chen W, Lv H, Liu S, Liu B, Zhu Y,Chen X, et al. (2017): National incidence of traumatic fractures in China: a retrospective survey of 512187 individuals. Lancet Glob Health 5(8):e807-e817.

3. Carpintero P, Caeiro JR, Carpintero R, Morales A, Silva S, Mesa M (2014): Complications of hip fractures: a review. World J Orthop 5(4):402-411.

4. Lawrence VA, Silverstein JH, Cornell JE, Pederson T, Noveck H, Carson JL (2003): Higher $\mathrm{Hb}$ level is associated with better early functional recovery after hip fracture repair.Transfusion, 43 (3): 1717.

5. Maraldi C, Ble A, Zuliani G, Guralnik JM, Mussi C, Fellin R, et al. (2006): Association between anemia and physical disability in older patients: role of comorbidity. Aging Clin Exp Res, 18 (6): 485.

6. Conteduca F, Massai F, Iorio R, Zanzotto E, Luzon D, Ferretti A (2009): Blood loss in computer-assisted mobile bearing total knee arthroplasty. A comparison of computer-assisted surgery with a conventional technique Int Orthop, 33 (9): 1609.

7. Tengberg PT, Foss NB, Palm H, Kallemose T, Troelsen A (2016): Tranexamic acid reduces blood loss in patients with extracapsularfractures of the hip: results of a randomised controlled trial Bone Joint Lett J, 98-B (2): 747. 
8. Marik PE Corwin, HL (2008): Efficacy of red blood cell transfusion in the critically ill: a systematic review of the literature. Crit Care Med, 36 (8): 2667.

9. Dunn CJ, Goa KL (1999): Tranexamic acid: a review of its use in surgery and other indications. Drugs, 57 (1): 1005.

10. Kazemi SM, Mosaffa F, Eajazi A, Kaffashi M, Daftari BL, Bigdeli MR, et al. (2010): The effect of tranexamic acid on reducing blood loss in cementless total hip arthroplasty under epidural anesthesia.Orthopedics, 33 (1): 17.

11. Duncan CM, Gillette BP, Jacob AK, Sierra RJ, Sotelo JS, Smith HM (2015): Venous thromboembolism and mortality associated with tranexamic acid use during total hip and knee arthroplasty. J Arthroplast 30(2):272-276.

12. Poeran J, Rasul R, Suzuki S, Danninger T, Mazumdar M, Opperer M, et al. (2014): Tranexamic acid use and postoperative outcomes in patients undergoing total hip or knee arthroplasty in the United States: retrospective analysis of effectiveness and safety. Bmj 349: 4829

13. Xiao C, Zhang S, Long N, Yu W, Jiang Y (2019): Is intravenous tranexamic acid effective and safe during hip fracture surgery? An updated meta-analysis of randomized controlled trials. Archives of orthopaedic and trauma surgery. 139(7):893-902.

14. Xie J, Hu Q, Huang Q, Ma J, Lei Y, Pei F (2017): Comparison of intravenous versus topical tranexamic acid in primary total hip and knee arthroplasty: an updated meta-analysis. Thromb Res 153:28-36.

15. Vijay BS, Bedi V, Mitra S, Das B (2013): Role of tranexamic acid in reducing postoperative blood loss and transfusion requirement in patients undergoing hip and femoral surgeries. Saudi J Anaesth. 7:29-32.

16. Tian S, Shen Z, Liu Y, Zhang Y, Peng A (2018): The effect of tranexamic acid on hidden bleeding in older intertrochanteric fracture patients treated with PFNA. Injury 49:680-684.

17. Virani SR, Dahapute AA, Panda I, Bava SS (2016): Role of local infiltration of tranexamic acid in reducing blood loss in peritrochanteric fracture surgery in the elderly population. Malays
Orthop J. 10:26.

18. Baruah RK, Borah PJ, Haque R (2016): Use of tranexamic acid in dynamic hip screw plate fixation for trochanteric fractures. J Orthop Surg (Hong Kong). 24:379.

19. Zhang P, He J, Fang Y, Chen P, Liang Y, Wang J (2017): Efficacy and safety of intravenous tranexamic acid administration in patients undergoing hip fracture surgery for hemostasis: a meta-analysis. Medicine. 96(21).

20. Qi YM, Wang HP, Li YJ, Ma BB, Xie T, Wang C, et al. (2019): The efficacy and safety of intravenous tranexamic acid in hip fracture surgery: A systematic review and meta-analysis. Journal of orthopaedic translation. 19:1-1.

21. Jansen AJ, Andreica S, Claeys M, D'Haese J, Camu F, Jochmans K (1999): Use of tranexamic acid for an effective blood conservation strategy after total knee arthroplasty. Br J Anaesth. 83:596-601.

22. Ekbäck G, Axelsson K, Ryttberg L, Edlund B, Kjellberg J, Weckström J, et al. (2000): Tranexamic acid reduces blood loss in total hip replacement surgery. Anesth Analg 91:1124-30.

23. Mohib Y, Rashid RH, Ali M, Zubairi AJ, Umer M (2015): Does tranexamic acid reduce blood transfusion following surgery for intertrochanteric fracture? A randomized control trial. J Pak Med Assoc. 65:S17.

24. Drakos A, Raoulis V, Karatzios K, Doxariotis N, Kontogeorgakos V, Malizos K, et al. (2016): Efficacy of local administration of tranexamic acid for blood salvage in patients undergoing intertrochanteric fracture surgery. J Orthop Trauma. 30:409.

25. Sadeghi (2007): Does a single bolus dose of tranexamic acid reduce blood loss and transfusion requirements during hip fracture surgery? A prospective randomized double blind study in 67 patients.

26. Yamasaki S, Masuhara K, Fuji T (2005): Tranexamic acid reduces postoperative blood loss in cementless total hip arthroplasty. J Bone Joint Surg Am. 87:766-70.

27. Lei J, Zhang B, Cong Y, Zhuang Y, Wei X, Fu Y, et al. (2017): Tranexamic acid reduces 
hidden blood loss in the treatment of intertrochanteric fractures with PFNA: a singlecenter randomized controlled trial. J Orthop Surg Res 12:124
28. Emara WM, Moez KK, Elkhouly AH (2014): Topical versus intravenous tranexamic acid as a blood conservation intervention for reduction of post-operative bleeding in hemiarthroplasty. Anesth Essays Res. 8:48

To cite this article: Ahmed A.Mahmoud, Hani A. Bassioony, Ahmed A. Elsheikh. Preoperative Versus Intraoperative Intravenous Tranexamic Acid Efficacy in Reducing Blood Loss in Hip Fracture Surgeries: A Randomized Controlled Trial. BMFJ 2021;38(orthopedic surgery):34-44. DOI: 10.21608/bmfj.2021.52955.1360 